\title{
Evaluating the Influences of Urban Expansion on the Concurrent Loss of Multiple Ecosystem Services in Drylands
}

\section{Shixiong Song}

Beijing Normal University

Chunyang He ( $\nabla$ hcy@bnu.edu.cn)

State Key Laboratory of Earth Surface Processes and Resource Ecology, Beijing Normal University

Zhifeng Liu

Beijing Normal University

Tao Qi

Beijing Normal University

\section{Research Article}

Keywords: Urban expansion, Data assimilation, Multiple ecosystem services, Ensemble Kalman filter, LUSD-urban model, Concurrent loss

Posted Date: July 1st, 2021

DOI: https://doi.org/10.21203/rs.3.rs-632977/v1

License: (c) (i) This work is licensed under a Creative Commons Attribution 4.0 International License. Read Full License 


\section{Evaluating the influences of urban expansion on the concurrent loss of multiple ecosystem services in drylands}

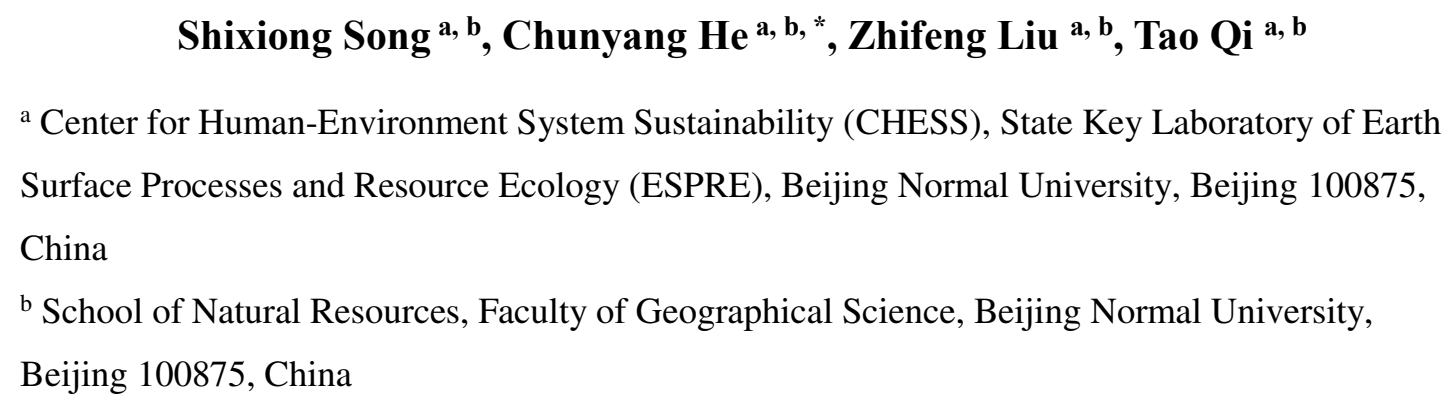

\section{Contact information:}

Shixiong Song: Xinjiekouwai Street No. 19, Haidian District, Beijing 100875, CN; E-mail: ssx1990@126.com; Tel.: +86-18-81157-3257.

Chunyang He: Xinjiekouwai Street No. 19, Haidian District, Beijing 100875, CN; E-mail: hcy@bnu.edu.cn; Tel.: +86-10-5880-4498; Fax: +86-10-5880-8460.

Zhifeng Liu: Xinjiekouwai Street No. 19, Haidian District, Beijing 100875, CN; E-mail: Zhifeng.liu@bnu.edu.cn; Tel.: +86-18-91162-8859.

Tao Qi: Xinjiekouwai Street No. 19, Haidian District, Beijing 100875, CN; E-mail: qitaocumt@163.com; Tel.: +86-13-85642-3398.

* Corresponding author at: State Key Laboratory of Earth Surface Processes and Resource Ecology, Beijing Normal University, Xinjiekouwai Street No. 19, Beijing 100875, China. Tel.: +8610-5880-4498; Fax: +86-10-5880-8460. E-mail: hcy@ bnu.edu.cn. 
Abstract:

Context Effectively estimating the influences of urban expansion on multiple ecosystem services (ESs) is of great importance for improving urban planning in drylands. However, there are some shortcomings in the existing urban expansion models, which lead to great uncertainties in the assessment of the influences of urban expansion on the concurrent loss of multiple ESs.

Objectives This study sought to effectively estimate the influences of urban expansion on the concurrent loss of multiple ESs in drylands.

Methods We combined the improved the urban expansion model and ES models to estimate the influences of urban expansion on five key ESs, including food production (FP), water retention (WR), air quality regulation (AQR), natural habitat quality (NHQ), and landscape aesthetic (LA).

Results The results showed that (1) our method can effectively evaluate the influences of urban expansion on the concurrent loss of multiple ESs in drylands, and the accuracy increased by more than $20 \%$ on average. (2) Under the effect of future urban expansion, FP, WR, AQR, NHQ and LA will accelerate the decline. (3) These five ESs will show concurrent degradation, and the degree will be further intensified. (4) Future urban expansion will occupy more cropland and grassland which will be the dominating reason for the intensified degradation of multiple ESs.

Conclusions We suggest that urban expansion through occupying a large amount of cropland and grassland should be strictly controlled via urban land planning to alleviate the potential influences of future urbanization on the concurrent loss of multiple ESs.

Keywords: Urban expansion; Data assimilation; Multiple ecosystem services; Ensemble Kalman filter; LUSD-urban model; Concurrent loss

\section{Introduction}

Ecosystem services (ESs) are the benefits that humans obtain from ecosystems (MEA, 2005). Urban expansion refers to the process of transforming nonurban land into urban land under the expansion of the urban scale in space (Bai et al., 2012). Urban expansion can promote regional socioeconomic development and enhance the quality of human life, but it can also affect the structure and function of ecosystems by removing vegetation and increasing the coverage of impervious surfaces, thus leading to the concurrent degradation of ESs (Yang et al., 2020; Gong and Liu, 2021). Previous studies have revealed that urban expansion has led to the concurrent loss of regulating services, provisioning services, and supporting services (Xie et al., 2018; Gomes et al., 2020; Hou et al., 2021), which has become an obstacle to regional sustainable development (MEA, 2005; Nelson et al., 2010). Drylands refer to areas with water shortages as the main feature, in which productivity and nutrient circulations are restricted by the water supply. Drylands account for $41.3 \%$ of the world's land area, in which $38 \%$ of the world's population lives (MEA, 2005). With the rapid expansion of urban land, the reduction in ESs is aggravated in drylands (Geist and Lambin, 2004). In the future, drylands will still take place large-scale urbanization (Seto et al., 2012; Zhou et al., 2019). Therefore, the effective assessment of the potential influences of future urban expansion on the concurrent loss of multiple ESs in drylands is of great importance for improving urban planning and promoting regional sustainable development.

At present, researchers have analyzed the influences of urban expansion on the concurrent loss of 
multiple ESs in drylands. For example, Pickard et al. (2016) analyzed the effects of urban expansion on surface water runoff, organic farming, nitrogen and phosphorus export, carbon sequestration and camping site suitability under different urban expansion scenarios in western North Carolina, USA, and found that different patterns of urban expansion can lead to the simultaneous loss of multiple ESs. Lyu et al. (2018) evaluated the effects of urbanization on ESs during the period of 1989-2015 in the northern part of Ningxia, China, and the results showed that urban expansion exerted negative impacts on carbon storage, crop production, sand fixation, habitat quality, and nutrient retention. Xie et al. (2018) assessed the impacts of urban expansion on water conservation, food production, air quality regulation, habitat quality and carbon storage in Beijing, China, during 2013-2040 and found that urban expansion will lead to the concurrent loss of multiple ESs in the future. However, there are still some uncertainties in existing studies. This is mainly because the existing urban expansion models have certain deficiencies in simulating future urban expansion. For example, the urban expansion model used by Xie et al. (2018) is based on the traditional cellular automation (CA) model. First, the traditional CA model assumes that the law of urban expansion remains unchanged from the past to the future and uses static model parameters in the simulation. Second, errors from data sources (such as field survey errors, digitization errors, and data conversion errors) will transmit and accumulate constantly in the CA model, thereby increasing the uncertainty associated with simulating future urban expansion (Zhang et al., 2015).

Improving the existing urban expansion model with the data assimilation method can lead to the more accurate simulation of future urban expansion, thereby reducing the uncertainties of the evaluation results of future urban expansion on the concurrent loss of multiple ESs. The data assimilation method directly or indirectly integrates multiple sources and multiple resolution observations by means of observation operators while weighing the uncertainties in the model and the observations to minimize the error of the entire system (Sakov and Bertino, 2011; Li et al., 2020). This method has been widely used in earth system sciences (Li et al., 2020). The ensemble Kalman filter (EnKF) is a widely used data assimilation method (Li et al., 2020). At present, previous studies have tried to use the EnKF method to improve the urban expansion model. For example, Zhang et al. (2015) optimized the CA urban expansion model using the EnKF method and found that the EnKF method can reduce error transmission and dynamically optimize the relevant parameters of the CA model, thereby improving the simulation capability of the urban expansion model. However, there is still a lack of studies using an improved urban expansion model based on data assimilation to evaluate the influences of future urban expansion on multiple ESs.

The objective of this paper is to improve the land use scenario dynamics-urban (LUSD-urban) model with data assimilation and then combine it with ES models to evaluate the potential influences of future urban expansion on the concurrent loss of multiple ESs. First, the Hohhot-Baotou-OrdosYulin (HBOY) urban agglomeration, China was chose as the study area and we mapped multiple key ESs by employing ES models. Then, we used the EnKF method to improve the LUSD-urban model and simulated future urban expansion. Finally, we estimated the potential influences of future urban expansion on the concurrent loss of multiple ESs to provide effective references for supporting regional urban planning.

\section{Study area and data}

\subsection{Study area}


The HBOY urban agglomeration is located in the middle of the drylands of northern China (E $106.5^{\circ}-122.3^{\circ}, \mathrm{N} 36.8^{\circ}-42.7^{\circ}$ ), with a total area of $1.75 \times 10^{5} \mathrm{~km}^{2}$ (Figure 1). The average elevation in the study area is approximately $1300 \mathrm{~m}$. The climate type a temperate continental monsoon climate, with a 30-year average temperature of approximately $8^{\circ} \mathrm{C}$ and a 30 -year average precipitation of approximately $320 \mathrm{~mm}$ (Song et al., 2020). There are 30 cities and 439 towns in the HBOY urban agglomeration.

In recent decades, the HBOY urban agglomeration has took place rapid urban expansion, which has caused serious impacts to the regional ESs, thereby bringing new challenges to biodiversity conservation and sustainable development (He et al., 2014; Sun et al., 2017; Song et al., 2020). For example, He et al. (2014) showed that urban expansion in the HBOY region from 1992 to 2014 caused the loss of $1178 \mathrm{~km}^{2}$ of natural habitat, posing negative impacts to regional species. Sun et al. (2017) found that regional urban expansion from 1990 to 2013 caused the four ESs of habitat quality, food production, meat production, and carbon sequestration to decline. Song et al. (2020) showed that urban land area increased from $151.29 \mathrm{~km}^{2}$ in 1990 to $1,230.86 \mathrm{~km}^{2}$ in 2017 in the HBOY area, which caused the natural habitat quality to decline. With the development of the regional economy and the relevant national policies (such as the plan for HBOY urban agglomeration and the "One Belt and One Road" initiative), the HBOY will also undergo rapid urban expansion in future, which will pose a huge threat to biodiversity and the surrounding ecosystem (Song et al., 2020; National Development and Reform Commission, 2018). Therefore, the HBOY urban agglomeration provides an appropriate study area for evaluating the potential influences of future urban expansion on the concurrent loss of multiple ESs in drylands.

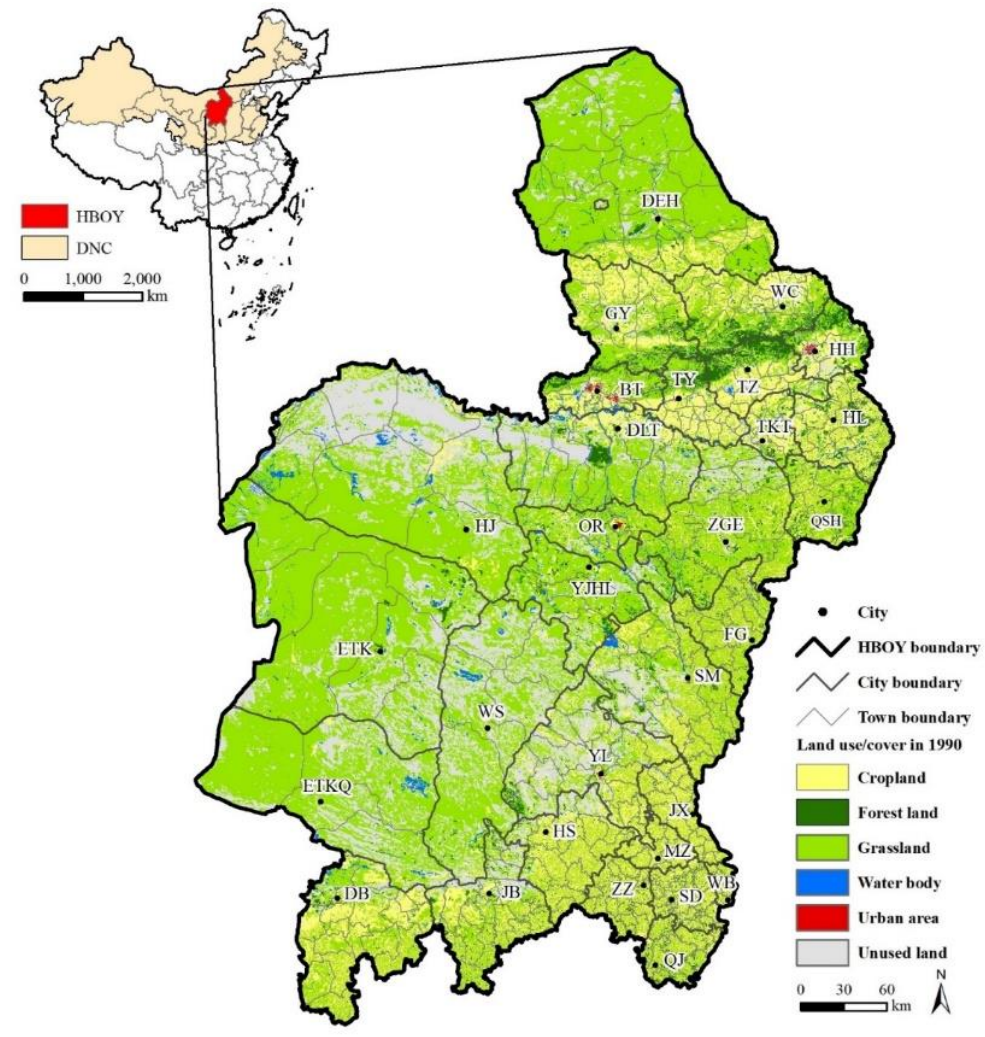

Fig. 1 Study area

Notes: The HBOY urban agglomeration includes thirty cities/towns ( Hohhot (HH), Baotou (BT), Ordos (OR), Yulin (YL), Tumotezuo (TZ), Tuoketuo (TKT), Helingeer (HL), Qingshuihe (QSH), Wuchuan (WC), Tumoteyou 
(TY), Guyang (GY), Daerhan (DEH), Dalate (DLT), Zhungeer (ZGE), Etuokeqian (ETKQ), Etuoke (ETK), Hangjin (HJ), Wushen (WS), Yijinhuoluo (YJHL), Jingbian (JB), Dingbian (DB), Fugu (FG), Shenmu (SM), Jiaxian (JX), Hengshan (HS), Mizhi (MZ), Zizhou (ZZ), Suide (SD), Wubao (WB), Qingjing (QJ)).

\subsection{Data}

In this study, the urban land data, land use/land cover (LULC) data, precipitation data, socioeconomic data, and basic geographic information data were used. Among them, the LULC data for 1990 comes from the Resource and Environmental Science Data Center of the Chinese Academy of Sciences (www.resdc.cn/data.aspx? DATAID=283). The resolution of LULC data is $30 \mathrm{~m}$, and the accuracy is above 90\% (Liu et al., 2010). The urban land data during the period of 1990 to 2017 comes from the dataset for the HBOY region obtained by the Google Earth Engine. The dataset includes urban land in 1990, 2000, 2010, and 2017, respectively. The resolution of urban land data is $30 \mathrm{~m}$, and the average Kappa is above 0.80 (Song et al., 2020). The annual precipitation data come from the spatial interpolation dataset of annual precipitation in China since 1980 from the Resource and Environmental Science Data Center of the Chinese Academy of Sciences (http://www.resdc.cn/data.aspx?DATAID=229). Socioeconomic data (such as GDP and total population) come from the Statistical Yearbook of Hohhot, Baotou, Ordos, and Yulin in 2017. The administrative boundaries, highways, railways, and national roads in the HBOY region come from the National Basic Geographic Information Center (http://ngcc.sbsm.gov.cn/). To ensure data consistency, all data used a unified Albers projection and were resampled to $100 \mathrm{~m}$.

\section{Methods}

\subsection{Mapping ESs}

According to the availability of data and the Millennium Ecosystem Assessment, we chose five key ESs, including supporting services (natural habitat quality), provisioning services (food production), regulating services (water retention and air quality regulation), and cultural services (landscape aesthetic).

\subsubsection{Natural habitat quality (NHQ)}

The Habitat Quality Module of the InVEST (the Integrated Valuation of Ecosystem Services and Tradeoff) model was used to quantify the NHQ. This module calculates NHQ based on the external influence factors and the sensitivity of a given LULC type. The main formula (Shape et al., 2016) is as follows:

$$
N H Q_{i j}=H_{k} \times\left(1-\frac{D_{i j}^{Z}}{D_{j i}^{Z}-K^{z}}\right)
$$

where $N H Q_{k x y}$ is the NHQ for grid $j$ in natural habitat type $i ; H_{i}$ is the suitability in natural habitat type $i ; D_{i j}^{Z}$ is the total threat for grid $j$ in natural habitat type $i ; K$ is the half-saturation constant and $Z$ is the scaling parameter. The related parameters are obtained from Song et al. (2020).

\subsubsection{Food production (FP)}

Referring to Li et al. (2014), we mapped the FP by LULC data. In the method, cropland yield vegetables, oil and grain, and grassland yield milk and mutton. The formula can be expressed as follows: 
171 where $F P_{i j}$ is the total FP service for grid $j$ under LULC type $i ; A_{j}$ is the area of grid $j$; and $p_{f i}$ is the per unit area yield for food $f$ in LULC type $i$. The $p_{f i}$ parameters can be found in the Supplementary file (Appendix A).

Appendix A Parameters for mapping food production in HBOY

\begin{tabular}{llllll}
\hline Land cover types & Cropland & & & \multicolumn{3}{c}{ Grassland } \\
\hline Items & Grain & Oil & Vegetable & Mutton & Milk \\
\cline { 2 - 6 } Yield per unit area $\left(\mathbf{t} / \mathbf{k m}^{\mathbf{2}}\right)$ & 321.11 & 19.21 & 108.60 & 3.76 & 83.78 \\
\hline
\end{tabular}

Note: The parameters were acquired from the Statistical Yearbook of Hohhot, Baotou, Ordos, and Yulin.

176

\subsubsection{Water retention (WR)}

Referring to Yang et al. (2015), the capability of vegetation (such as cropland, grassland, and forest land) to intercept surface runoff was calculated to quantify WR. The formula is as follows:

$$
W R_{i j}=A_{j} \times P_{i} \times K \times R_{i j}
$$

where $W R_{i j}$ is the total WR for grid $j$ in LULC type $i ; A_{j}$ is the area of grid $j ; P_{j}$ is the 27-year (1990-2017) averaged precipitation for grid $j . K$ is the surface runoff coefficient, which is set to 0.6 based on Yang et al. (2015). $R_{i j}$ is the proportion of surface runoff relative to total rainfall. The $R_{k x y}$ parameters can be found in the Supplementary file (Appendix B).

\section{Appendix B Parameters for mapping water retention, and air quality regulation in HBOY}

\begin{tabular}{lllllll}
\hline $\begin{array}{l}\text { Ecosystem } \\
\text { services }\end{array}$ & Items & Cropland & Forest land & Grassland & Unused land & References \\
\hline Water retention & $\begin{array}{l}\text { Coefficients of } \\
\text { rainwater runoff }\end{array}$ & 11.5 & 13.6 & 12.1 & 0 & Zhang et al. (2012) \\
$\begin{array}{l}\text { Air quality } \\
\text { regulation }\end{array}$ & $\begin{array}{l}\mathrm{PM} \mathrm{M}_{10} \text { capture } \\
(\mathrm{Kg} / \mathrm{ha})\end{array}$ & 9.2 & 62 & 27 & 0 & $\begin{array}{l}\text { Landuyt et al. } \\
(2016)\end{array}$ \\
\hline
\end{tabular}

\subsubsection{Air quality regulation (AQR)}

Referring to Landuyt et al. (2016), the capability of vegetation to adsorb the $\mathrm{PM}_{10}$ (particulate matter with a particle size below $10 \mu \mathrm{m}$ ) was used to quantify the AQR service. The formula is as follows:

$$
A Q R_{i j}=A_{j} \times P M_{i j}
$$

where $A Q R_{i j}$ is the total retention volume of $\mathrm{PM}_{10}$ for grid $j$ in LULC type $i ; A_{x y}$ is the area of grid $j$; and $P M_{i j}$ is the retention volume of per unit area $\mathrm{PM}_{10}$ for grid $j$ in LULC type $i$. The $P M_{i j}$ parameters can be found in the Supplementary file (Appendix B).

\subsubsection{Landscape aesthetic (LA)}

According to Cui et al. (2019), the visual quality index is used to quantify the LA, which represent the aesthetic appeal of natural landscapes to tourists. The formula is as follows:

$$
V Q I_{j}=V Q I_{j}^{p}+V Q I_{j}^{b}+V Q I_{j}^{g}+V Q I_{j}^{h}+V Q I_{j}^{a}
$$


where $V Q I_{j}$ is the total visual quality index score for grid $j$, with the range of $0-5 ; V Q I_{j}^{p}$ is the terrain factor score for grid $j ; V Q I_{j}^{b}$ is the water bodies factor score for grid $j ; V Q I_{j}^{g}$ is the natural vegetation factor score for grid $j ; V Q I_{j}^{h}$ is the urbanization factor score for grid $j$; and $V Q I_{j}^{a}$ is the natural landscape accessibility factor score for grid $j$.

\subsection{Simulating urban expansion from 2017 to 2050}

\subsubsection{Improved LUSD-urban model based on EnKF}

(1) LUSD-urban model

According to He et al. (2016), the LUSD-urban model consists of two parts: the urban land demand module and the urban land space allocation module. In the demand module, a linear regression model is established based on the urban land area and urban population to predict the total urban land demand in the future. In the space allocation module, whether nonurban grids are converted into urban grids is mainly affected by their suitability, the inheritance attributes of the LULC class, neighborhood effects, and random perturbations in urban expansion. The probability for the nonurban grid $(x, y)$ with land-use type $K$ transformed into the urban grid at time $t$ can be expressed as:

$P_{K, x, y}^{t}=\left(\sum_{i=1}^{m-2} W_{i} \times S_{i, x, y}^{t}+W_{m-1} \times N_{x, y}^{t}-W_{m} \times I_{K, x, y}^{t}\right) \times \prod_{r=1} E C_{r, x, y}^{t} \times \prod_{l=1} P C_{l, x, y}^{t} \times V_{x, y}^{t}$

where $\sum_{i=1}^{m-2} W_{i} \times S_{i, x, y}^{t}$ is the suitability of the nonurban grids $(x, y)$ transformed into an urban grid at time $t ; S_{i, x, y}^{t}$ is the suitability factor $i ; W_{i}$ is the weight of suitability factor $i ; N_{x, y}^{t}$ is the effects of neighborhood grids; $W_{m-1}$ is the weights of neighborhood grids; $I_{K, x, y}^{t}$ is the inheritance attribute of grid $(x, y)$ at time $t ; W_{m}$ is the weight of different LULC types; $\prod_{r=1} E C_{r, x, y}^{t}$ is the ecological constraints, which is a binary variable; $\prod_{l=1} P C_{l, x, y}^{t}$ is the land planning policy constraints, which is also a binary variable; and $V_{x, y}^{t}$ is the random perturbation factor.

(2) EnKF model

The EnKF model can be divided into two stages: prediction and update. In the prediction stage, the simulation of the process model is performed using the initial state set obtained by random sampling to obtain the prediction set, and the Kalman gain is calculated by employing the prediction set. In the update stage, the prediction set is updated by the observations and Kalman gain, and the updated result is used as the analysis value set. The mean of the analysis value set is the posterior estimate of the model and will continue to act as the new state set that participates in the next cycle (Sakov and Bertino, 2011; Zhang et al., 2015).

The EnKF model achieves its goal of dynamic data assimilation by iterating the above two stages. The main formula are as follows:

1) Initialization. The random variables $X_{i}(i=1,2 \ldots, N)$ were obtained by the Monte Carlo method. In our study, the state variable is the urban land data in the initial year.

2) Prediction. The state variable at time $k$ is used to estimate the state variable at time $k+1$. The formula is as follows:

$$
X_{k+1}^{f}=\boldsymbol{M}\left(X_{k}^{a}\right)+w_{k} \quad w_{k} \sim N(0, Q)
$$

where $X_{k+1}^{f}$ is the prediction set at time $k+1 ; X_{k}^{a}$ is the analysis value set at time $k$; and $\boldsymbol{M}()$ is the state change relationship from time $k$ to time $k+1$, which is generally a nonlinear operator. In our 
study, it is the LUSD-urban model. $w_{k}$ represents the model error, which conforms to a Gaussian distribution with an expected value of zero and a covariance of $Q$.

3) Update. The prediction set is corrected by integrating the observations and Kalman gain. The formula is as follows:

$$
\begin{gathered}
X_{k+1}^{a}=X_{k+1}^{f}+\boldsymbol{K}_{k+1}\left[Y_{k+1}-H_{k+1}\left(X_{k+1}^{f}\right)+v_{k}\right] \quad v_{k} \sim N(0, R) \\
\bar{X}_{k+1}^{a}=\frac{1}{N} \sum_{i=1}^{N} X_{i, k+1}^{a}
\end{gathered}
$$

where $X_{k+1}^{a}$ is the analysis value set at time $k+1 ; \boldsymbol{K}_{\boldsymbol{k}+\mathbf{1}}$ is the Kalman gain at time $k+1 ; Y_{k+1}$ is the observation set at time $k+1 ; H_{k+1}$ is the observation operator at time $k+1$; and $v_{k}$ is the observation error, which also conforms to a Gaussian distribution with an expected value of zero and a covariance of $R . \bar{X}_{k+1}^{a}$ is the mean of the analysis value set at time $k+1$.

$$
K_{k+1}=P_{k+1}^{f} H^{T}\left(H P_{k+1}^{f} H^{T}+R_{k}\right)^{-1}
$$

$$
P_{k+1}^{f} H^{T}=\frac{1}{N-1} \sum_{i=1}^{N}\left(X_{i, k+1}^{f}-\bar{X}_{k+1}^{f}\right)\left(H X_{i, k+1}^{f}-H \bar{X}_{k+1}^{f}\right)^{T}
$$$$
H P_{k+1}^{f} H^{T}=\frac{1}{N} \sum_{i=1}^{N}\left[H\left(X_{i, k+1}^{f}\right)-H\left(\bar{X}_{k+1}^{f}\right)\right]\left[H\left(X_{i, k+1}^{f}\right)-H\left(\bar{X}_{k+1}^{f}\right)\right]^{T}
$$

where $P_{k+1}^{f}$ is the covariance of the prediction error at time $k+1$ and $R_{k}$ is the covariance of the observation error at time $k$.

4) Judgment. If the end stage of assimilation has been reached, the model is terminated. Otherwise, the model procedure returns to step 2).

\section{(3) Combining the LUSD-urban model and the EnKF model}

First, we used the factor data (i.e., distances to city centers, distances to highways, distances to rivers, and distances to national roads), historical urban expansion data and the LUSD-urban model to build the urban expansion model and obtain the initial parameters (Fig. 2). 


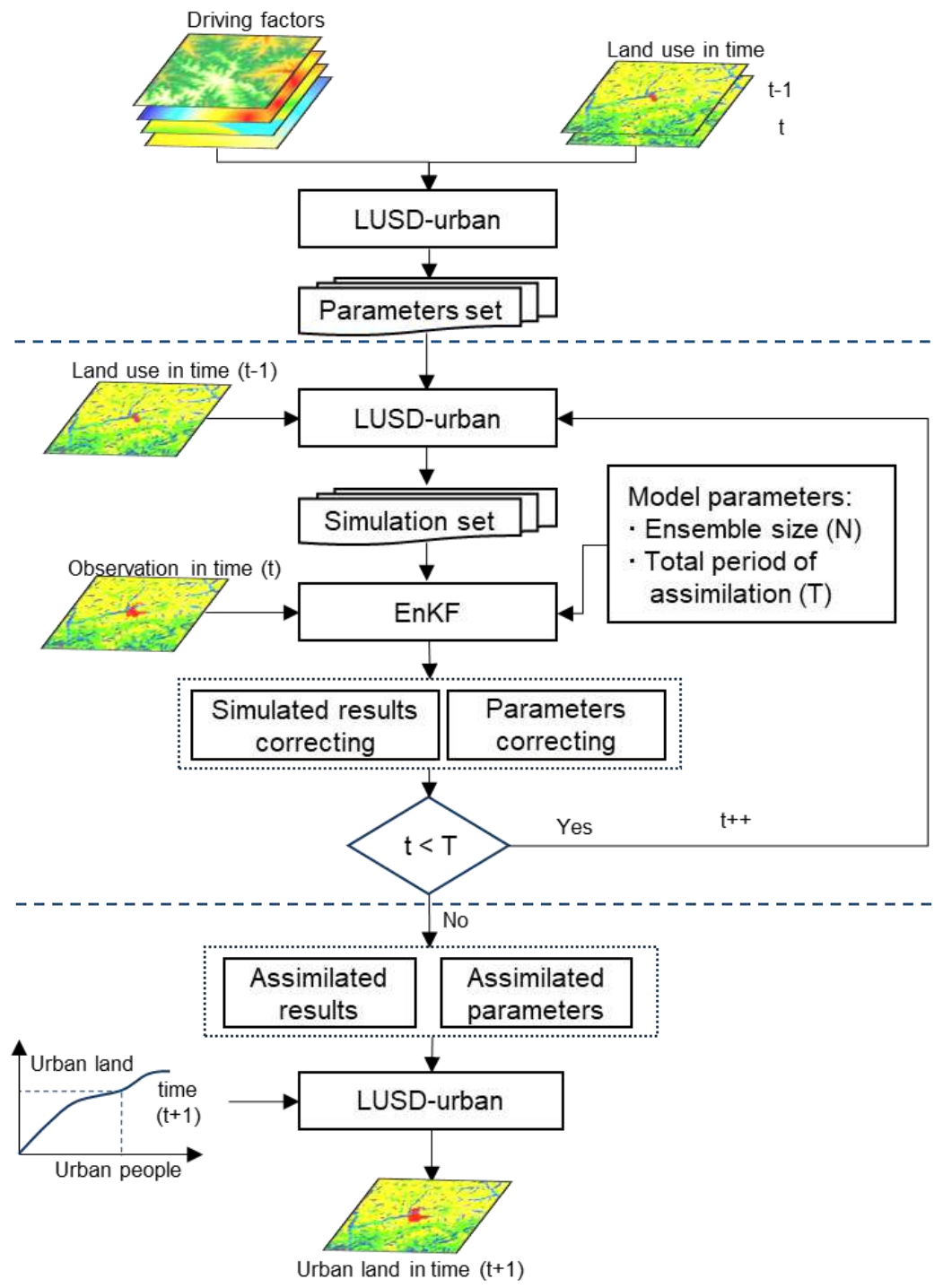

Fig. 2 The framework of the improved LUSD-urban model

Second, we simulated the urban land with the LUSD-urban model. The EnKF model requires the input data to be non-Boolean, while the simulation results of the LUSD-urban model only have two states, namely, urban (cell state is 1) and nonurban (cell state is 0). According to Zhang et al. (2015), we divided the study area into several grids, and each grid included a certain number of cells. We calculated the urban expansion intensity of each grid as follows:

$$
\rho_{i, j}^{t}=\frac{\sum m \times m \operatorname{con}\left(s_{i, j}=u r b a n\right)}{m \times m}
$$

where $\rho_{i, j}^{t}$ is the urban expansion intensity for grid $(i, j)$ at time $t ; \sum_{m \times m} \operatorname{con}\left(s_{i, j}=u r b a n\right)$ is the total number of urban cells in grid $(i, j)$; and $m \times m$ is the total number of cells in grid $(i, j)$.

Third, the simulation results and parameters (the weights of factors) of LUSD-urban were corrected by integrating the EnKF model and the actual urban land data. The main steps were as follows: (a) Several grids are randomly selected as observation points, and the urban expansion intensity of those grids is the observation value. (b) The LUSD-urban model is used to simulate urban land in the same year of data assimilation, and the urban expansion intensity of the simulation results is calculated as the prediction value. (c) The Kalman is calculated gain using the observation value and the 
prediction value based on Eq. (10). (d) The simulation results are corrected using the Kalman gain based on Eq. (8), and the parameters of the LUSD-urban model are corrected as follows:

$$
W_{k+1}^{a}=W_{k+1}^{f}+K_{k+1}\left[Y_{k+1}-H_{k+1}\left(X_{k+1}^{f}\right)+v_{k}\right]
$$

where $W_{k+1}^{a}$ is the analysis value set of weights at time $k+1$ and $W_{k+1}^{f}$ is the prediction set of weights set at time $k+1$.

$$
W_{k+1}^{f}=W_{k}^{a}+\boldsymbol{l}_{\boldsymbol{k}}
$$

where $W_{k}^{a}$ is the analysis value set of weights set at time $k$ and $l_{k}$ is the error of weights, which is represents Gaussian white noise.

Finally, we put the corrected results and parameters into the LUSD-urban model as the initial inputs of the next cycle until all observations have been assimilated. After assimilation, the improved LUSD-urban model can be used to simulate future urban expansion.

In our study, we put LULC in 2000, elevation, slope, distance to the city centers, distance to rivers, distance to highways, distance to railways, and distance to national roads into the LUSD-urban model and used the Monte Carlo method to obtain the initial parameters, including the weights of factors and the simulation result of urban land in 2010 (Eq. 6 and 7). Then, the simulated urban land in 2010 and actual urban land in 2010 were transformed into urban expansion intensity and put into the EnKF model for data assimilation (Eq. 8 and 14). Finally, the assimilated simulation results and parameters were input into the LUSD-urban model to predict the urban land area in 2017, and the validation of the model was verified with the actual urban land area in 2017. The results showed that the Kappa coefficient of the improved LUSD-urban model with the EnKF method was 0.64, which suggests that that the model is able to simulate future urban land expansion (Appendix C). 
Appendix C Parameters used in the improved LUSD-urban model

\begin{tabular}{lccc}
\hline \multirow{2}{*}{ Factors } & Initial & 2000-2010 & 2010-2017 \\
\cline { 3 - 4 } & parameters & Assimilated parameters & Assimilated parameters \\
\hline Distance to urban centers & 0.140 & 0.168 & 0.168 \\
Elevation & 0.100 & 0.042 & 0.042 \\
Distance to railways & 0.150 & 0.154 & 0.154 \\
Distance to highways & 0.040 & 0.033 & 0.033 \\
Slope & 0.110 & 0.103 & 0.103 \\
Distance to roads & 0.080 & 0.069 & 0.069 \\
Neighborhood effects & 0.080 & 0.103 & 0.103 \\
Inheritance attributes & 0.300 & 0.328 & 0.328 \\
Accuracy Kappa & & 0.72 & 0.64 \\
assessment Overall & & $99.86 \%$ & $99.73 \%$ \\
accuracy & & & \\
\hline
\end{tabular}

297

\subsubsection{Projecting urban expansion from 2017 to 2050}

According to He et al. (2016), the regression model was used to forecast urban land demand in future. In this study, we used the urban land area and urban population in 1990, 2000, 2010, and 2017 to build a linear regression model. The formula is as follows:

$$
S=3.69 \times P o p-817.71
$$

where $S$ is the urban land area; Pop is the urban population. The $R^{2}$ value of the linear regression model is 0.97 .

Then, we used urban population and time to construct a regression model to forecast the urban population in 2050 . The formula is as follows:

$$
\text { Pop }=3.69 \times y-817.71
$$

where Pop is the urban population and $y$ is the year. The $R^{2}$ value is 0.98 .

Finally, we predicted that the urban land area in the HBOY region will reach $2498.25 \mathrm{~km}^{2}$ in 2050 based on Eq. (16) and (17). On this basis, the improved LUSD-urban model was used to project the urban expansion in the HBOY urban agglomeration from 2017 to 2050.

\subsection{Assessing the potential impacts of future urban expansion on the concurrent loss of} multiple ESs

According to Xie et al. (2018), we calculated correlation coefficient to quantify the potential influences of future urban expansion on the concurrent loss of multiple ESs. First, the spatial patterns of the five ESs were mapped by the ES models outlined in Section 3.1, and their changes were calculated from 1990-2017 and 2017-2050. Changes were calculated as follows: 
where $\Delta E S_{i, j}$ is the change in ecosystem service $i$ in township $j$ from year $t_{1}$ to year $t_{2} ; E S_{i, j}^{t_{1}}$ is ecosystem service $i$ in township $j$ in year $t_{t}$; and $E S_{i, j}^{t_{1}}$ is ecosystem service $i$ in township $j$ in year $t_{2}$. If $\Delta E S_{i, j}$ is more than zero, it indicates that ESs are enhanced. If $\Delta E S_{i, j}$ is negative, it indicates that ESs are degraded and that urban expansion has a negative impact on ESs.

Then, Pearson's correlation coefficient was calculated to analyze whether there was concurrent loss between the different ESs and quantify the size of the concurrent loss caused by urban expansion. The calculation of the correlation coefficient is as follows:

$$
R=\operatorname{cov}(X, Y) /(\sqrt{D(X)} \sqrt{D(Y)})
$$

where $R$ is the correlation coefficient between ecosystem service $X$ and $Y ; \operatorname{cov}(X, Y)$ is the covariance between ecosystem service $X$ and $Y ; D(X)$ is the variance of ecosystem service $X$; and $D(Y)$ is the variance of ecosystem service $Y$.

When a pair of ESs revealed a trend of deterioration along with urban expansion $\left(\Delta E S_{i, j}<0\right)$, they also had a significant and strong positive linear relationship $(\mathrm{R}>0.5, \mathrm{P}<0.01)$ both before and after urban expansion, which indicates that urban expansion caused these two ESs to be concurrently lost. In addition, the change in the correlation coefficient represents the change in the magnitude of the concurrent loss caused by urban expansion.

\section{Results}

\subsection{Urban expansion from 1990 to 2050 in the HBOY Region}

The HBOY region experienced rapid urban expansion from 1990 to 2017. The urban land area increased from $151.29 \mathrm{~km}^{2}$ to $1230.86 \mathrm{~km}^{2}$, representing a 7.14-fold increase, with an average annual growth rate of $19.29 \%$. Among them, Baotou, Hohhot, Ordos, and Yulin are the four cities with the largest increase in urban land, with areas of $320.91 \mathrm{~km}^{2}, 214.77 \mathrm{~km}^{2}, 113.78 \mathrm{~km}^{2}$, and 80.50 $\mathrm{km}^{2}$, respectively. These cities accounted for $67.62 \%$ of the total area of urban expansion in the HBOY region (Figure 3A).

HBOY area will continue to take place rapid urban expansion from 2017 to 2050 . The area of urban land will reach $2498.25 \mathrm{~km}^{2}$ in 2050 , with an increase of $102.97 \%$. The new urban land will be mainly distributed in Hohhot, Baotou, Yulin, and Ordos, with areas of $370.38 \mathrm{~km}^{2}, 320.53 \mathrm{~km}^{2}$, $114.38 \mathrm{~km}^{2}$, and $114.07 \mathrm{~km}^{2}$, respectively. These cities will account for $72.54 \%$ of the total area of newly increased urban land throughout the whole region (Fig. 3B). 


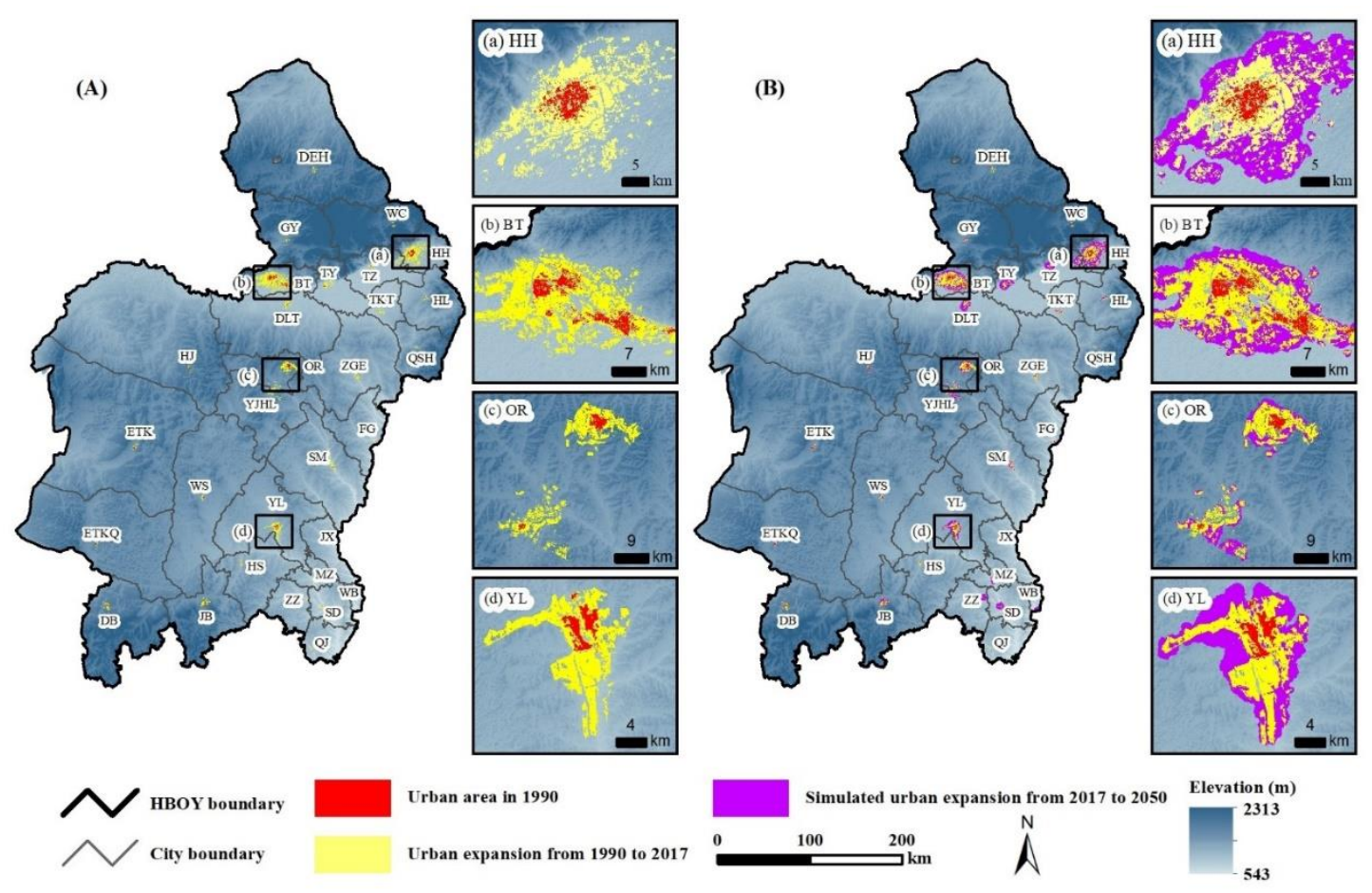

Fig. 3 Urban expansion in HBOY from 1990 to 2050. (A) actual urban expansion during 19902017, (B) simulated urban expansion during 2017-2050.

Note: please refer to Fig. 1 for the full names of cities

\subsection{The influences of urban expansion on the concurrent loss of ESs from 1990 to 2017}

Urban expansion from 1990 to 2017 led to a decline in the five ESs in the HBOY region. Among them, the loss of FP was the largest, which was reduced from $132.87 \mathrm{t} / \mathrm{km}^{2}$ to $131.77 \mathrm{t} / \mathrm{km}^{2}$, for a total decrease of $0.83 \%$. The loss of LA was the smallest, which was reduced from 3.85 to 3.84 , decreasing by $0.26 \%$. WR, AQR and NHQ decreased by $0.54 \%, 0.43 \%$ and $0.39 \%$, respectively (Fig. 4). Spatially, urban expansion in Baotou and Hohhot had the most serious impacts on the evaluated ESs (Fig. 4). Urban expansion in Baotou from 1990 to 2017 led to reductions in NHQ, FP, WR, AQR, and LA by $8.09 \%, 14.98 \%, 9.50 \%, 7.63 \%$, and $5.17 \%$, respectively (Table 1 ). Hohhot decreased by $4.60 \%, 12.32 \%, 7.02 \%, 4.51 \%$ and $4.15 \%$, respectively (Table 1 ).

From 1990 to 2017, urban expansion caused the concurrent loss of three pairs of ESs, and the magnitude showed an increasing trend. The related three pairs of ESs were NHQ and AQR, FP and WR, and WR and LA. Specifically, the correlation coefficients of the three pairs of ESs in 1990 and 2017 were greater than 0.5 and passed the significance level at 0.01 (Fig. 5a, b). Among them, the correlation coefficients of NHQ and AQR were the largest in 1990 and 2017 and were both greater than 0.8 , which indicated that the concurrent loss of NHQ and AQR caused by urban expansion was most severe in 1990-2017. In addition, the Pearson's correlation coefficients of the three pairs of ESs showed an increasing trend, indicating that the intensity of the concurrent loss caused by urban expansion was increasing. Among them, the intensity of the concurrent loss of WR and LA increased the most, and the correlation coefficients increased from 0.57 to 0.62 , representing an increase of 
Table 1 Influences of urban expansion on ecosystem services in HBOY during 1990-2017

\begin{tabular}{|c|c|c|c|c|c|c|c|c|c|c|}
\hline & \multicolumn{2}{|l|}{ NHQ } & \multicolumn{2}{|c|}{ FP（t/ha $)$} & \multicolumn{2}{|c|}{ WR（t/ha） } & \multicolumn{2}{|c|}{ AQR (kg/ha) } & \multicolumn{2}{|l|}{$\mathbf{L A}$} \\
\hline & 1990 & $\begin{array}{l}1990- \\
2017 \\
\text { Loss } \\
(\%)\end{array}$ & 1990 & $\begin{array}{l}1990- \\
2017 \\
\text { Loss } \\
(\%)\end{array}$ & 1990 & $\begin{array}{l}1990- \\
2017 \\
\text { Loss } \\
(\%)\end{array}$ & 1990 & $\begin{array}{l}1990- \\
2017 \\
\text { Loss } \\
(\%)\end{array}$ & 1990 & $\begin{array}{l}1990- \\
2017 \\
\text { Loss } \\
(\%)\end{array}$ \\
\hline HBOY & 0.5116 & 0.39 & 1.33 & 0.83 & 202.40 & 0.54 & 19.09 & 0.43 & 3.85 & 0.27 \\
\hline HH & 0.4954 & 4.60 & 1.69 & 12.32 & 238.63 & 7.02 & 23.35 & 4.51 & 4.03 & 4.15 \\
\hline BT & 0.5089 & 8.09 & 1.53 & 14.98 & 202.76 & 9.50 & 21.32 & 7.63 & 4.33 & 5.17 \\
\hline ER & 0.5865 & 3.48 & 1.29 & 6.93 & 239.75 & 4.85 & 20.74 & 4.13 & 4.13 & 2.01 \\
\hline YL & 0.3487 & 1.10 & 1.36 & 1.29 & 188.79 & 1.17 & 13.44 & 1.10 & 4.04 & 0.47 \\
\hline $\mathbf{T Z}$ & 0.4694 & 1.45 & 1.95 & 0.87 & 259.89 & 1.06 & 24.95 & 0.95 & 4.28 & 0.55 \\
\hline TK & 0.3273 & 0.35 & 2.37 & 0.64 & 238.53 & 0.45 & 17.47 & 0.25 & 4.36 & 0.33 \\
\hline HL & 0.3679 & 0.19 & 2.51 & 0.25 & 278.73 & 0.21 & 20.48 & 0.19 & 4.22 & 0.11 \\
\hline QS & 0.5942 & 0.11 & 1.65 & 0.06 & 311.02 & 0.08 & 24.69 & 0.12 & 4.37 & 0.05 \\
\hline WC & 0.4883 & 0.06 & 2.04 & 0.19 & 275.15 & 0.10 & 23.45 & 0.06 & 3.71 & 0.07 \\
\hline TY & 0.3544 & 0.65 & 2.40 & 1.51 & 242.24 & 1.04 & 18.55 & 0.77 & 4.37 & 0.54 \\
\hline GY & 0.4468 & 0.05 & 2.14 & 0.15 & 233.93 & 0.09 & 20.46 & 0.06 & 3.87 & 0.06 \\
\hline DE & 0.6743 & 0.04 & 1.03 & 0.03 & 165.82 & 0.04 & 23.20 & 0.04 & 3.21 & 0.02 \\
\hline DL & 0.4779 & 0.23 & 1.12 & 0.34 & 176.47 & 0.26 & 16.65 & 0.36 & 4.12 & 0.12 \\
\hline ZG & 0.5729 & 0.12 & 1.36 & 0.08 & 267.48 & 0.10 & 21.96 & 0.13 & 4.32 & 0.06 \\
\hline ETQ & 0.5872 & 0.04 & 0.65 & 0.04 & 150.39 & 0.04 & 18.79 & 0.04 & 3.32 & 0.02 \\
\hline ET & 0.6480 & 0.04 & 0.69 & 0.05 & 147.65 & 0.05 & 21.23 & 0.05 & 3.76 & 0.02 \\
\hline HJ & 0.4673 & 0.07 & 0.63 & 0.07 & 101.45 & 0.09 & 14.14 & 0.07 & 3.77 & 0.02 \\
\hline WS & 0.4870 & 0.09 & 0.55 & 0.25 & 150.34 & 0.13 & 15.06 & 0.11 & 3.54 & 0.05 \\
\hline YJ & 0.6268 & 0.62 & 0.86 & 0.94 & 229.67 & 0.68 & 22.35 & 0.59 & 4.09 & 0.29 \\
\hline $\mathbf{J B}$ & 0.4191 & 0.32 & 1.95 & 0.74 & 281.24 & 0.49 & 18.43 & 0.41 & 3.82 & 0.27 \\
\hline DB & 0.3906 & 0.19 & 2.37 & 0.33 & 261.26 & 0.23 & 17.49 & 0.26 & 3.47 & 0.15 \\
\hline FG & 0.5184 & 0.23 & 2.06 & 0.25 & 306.70 & 0.21 & 20.78 & 0.22 & 4.31 & 0.11 \\
\hline SM & 0.4430 & 0.31 & 1.66 & 0.47 & 252.13 & 0.29 & 17.26 & 0.23 & 4.18 & 0.17 \\
\hline $\mathbf{J X}$ & 0.3225 & 0.05 & 2.93 & 0.04 & 314.73 & 0.04 & 16.41 & 0.04 & 4.50 & 0.02 \\
\hline HS & 0.3318 & 0.28 & 2.49 & 0.17 & 272.93 & 0.19 & 15.83 & 0.25 & 4.26 & 0.10 \\
\hline $\mathbf{M Z}$ & 0.3107 & 0.30 & 3.07 & 0.55 & 325.55 & 0.42 & 16.54 & 0.38 & 4.55 & 0.21 \\
\hline $\mathbf{Z Z}$ & 0.3786 & 0.08 & 2.77 & 0.17 & 339.05 & 0.13 & 19.99 & 0.10 & 4.45 & 0.06 \\
\hline SD & 0.3648 & 0.30 & 2.77 & 0.25 & 336.15 & 0.24 & 20.91 & 0.24 & 4.59 & 0.13 \\
\hline WB & 0.3667 & 0.69 & 2.74 & 0.19 & 318.94 & 0.17 & 18.18 & 0.17 & 4.69 & 0.14 \\
\hline QJ & 0.4714 & 0.12 & 2.31 & 0.10 & 350.18 & 0.11 & 23.30 & 0.10 & 4.60 & 0.05 \\
\hline
\end{tabular}






Fig. 4 Influences of urban expansion on ecosystem services in HBOY during 1990-2017. Notes: NHQ, FP, WR, AQR and LA refer to natural habitat quality, food production, water retention, air quality regulation and landscape aesthetic, respectively.
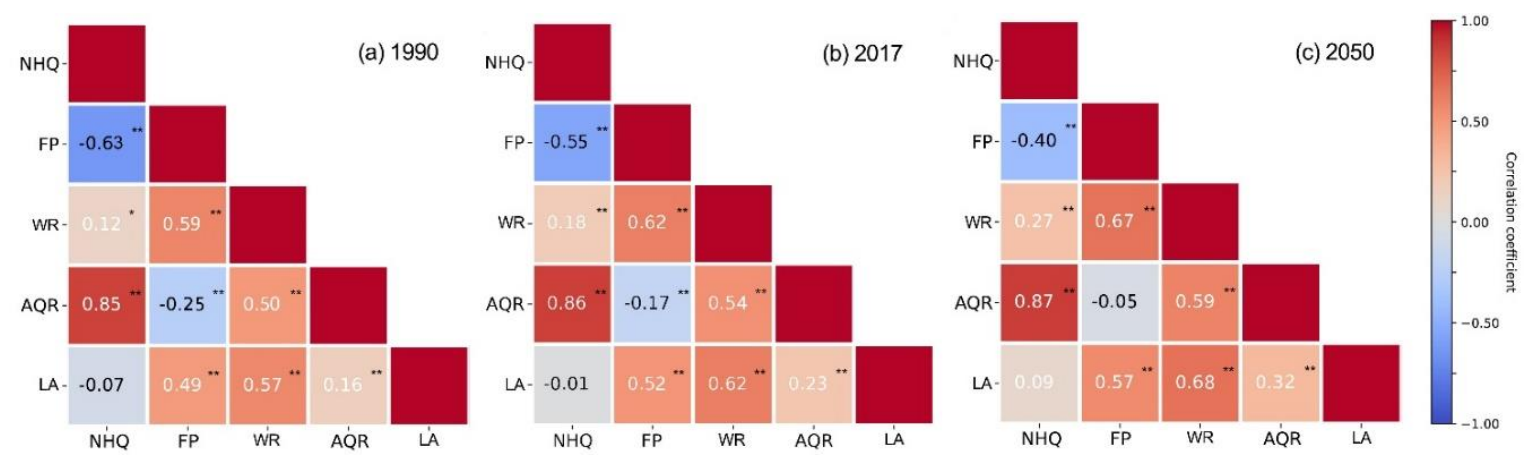

Fig. 5 The dynamic relationships between pairs of ecosystem services in HBOY from 1990 to 2050. (a) Pearson's correlation coefficients in 1990. (b) Pearson's correlation coefficients in 2017. (c) Pearson's correlation coefficients in 2050.

Notes: (1) Please refer to figure 4 for an explanation of the abbreviations. (2) The numbers are the Pearson's correlation coefficients between pairs of ecosystem services.

* Significant at $0.05 ; * *$ Significant at 0.01 .

\subsection{The potential influences of urban expansion on the concurrent loss of ESs from 2017 to} 2050

With the expansion of urban land in future, the five key ESs will continue to degrade. From 2017 to 2050, FP, WR, NHQ, AQR, and LA will be reduced by $1.34 \%, 0.81 \%, 0.65 \%, 0.60 \%$, and $0.35 \%$, respectively, which will be greater that the reduction caused by urban expansion from 1990 to 2017. 
Among them, the loss of FP will be the most serious and decreased from $131.77 \mathrm{t} / \mathrm{km}^{2}$ to 130.01 $\mathrm{t} / \mathrm{km}^{2}$. The loss of LA was the smallest and decreased from 3.84 to 3.83 (Fig. 6). Spatially, the influences of urban expansion on regional ESs in Baotou and Hohhot will still be the most serious (Fig. 6). Among them, urban expansion in Hohhot from 2017 to 2050 will lead to reductions in FP, WR, NHQ, AQR, and LA by $8.91 \%, 26.75 \%, 13.55 \%, 7.99 \%$, and 6.56\%, respectively (Table 2). Those of Baotou will decrease by $11.52 \%, 20.65 \%, 12.04 \%, 8.94 \%$ and $5.19 \%$, respectively (Table 2).

Urban expansion will lead to the concurrent loss of five pairs of ESs from 2017 to 2050, and the intensity will become increasingly serious. Among them, NHQ and AQR, FP and WR, and WR and LA will still show a concurrent loss. At the same time, FP and LA and WR and AQR will also reveal concurrent losses in future. Specifically, the related ESs pairs will reveal a significant strong positive correlation in 2017 and 2050 (Pearson's correlation coefficients will be greater than 0.5 and pass the significance at 0.01) (Fig. 5b, c). The correlation between NHQ and AQR will still be the highest, which indicates that the concurrent loss caused by urbanization will still be the most severe in the future. In addition, with the advancement of urban land in the future, the Pearson's correlation coefficients of the five pairs of ESs will also increase, indicating that urban expansion from 2017 to 2050 in the HBOY region will cause the concurrent loss of the five pairs of ESs, which will become increasingly serious. Among them, the intensity of the concurrent loss between WR and AQR will increase the most, and its correlation coefficient will increase from 0.54 to 0.59 , representing an increase of 0.05 (Fig. 5b, c).

Urban expansion will aggravate the loss of ESs and the degree of the concurrent loss of ESs in the future. With the increase in urban areas, the average annual loss of the five evaluated ESs in 20172050 will be significantly higher than that in 1990-2017 (Figure 7). The most significant change in the loss of ESs will be that of FP. Compared with 1990-2017, the average annual loss of FP in 20172050 will be $0.04 \%$, representing an increase of $32.50 \%$. In addition, compared with 1990-2017, the pairs of ESs exhibiting concurrent loss will increase from three pairs to five pairs, and the correlation coefficients will continue to show an increasing trend (Fig. 5).

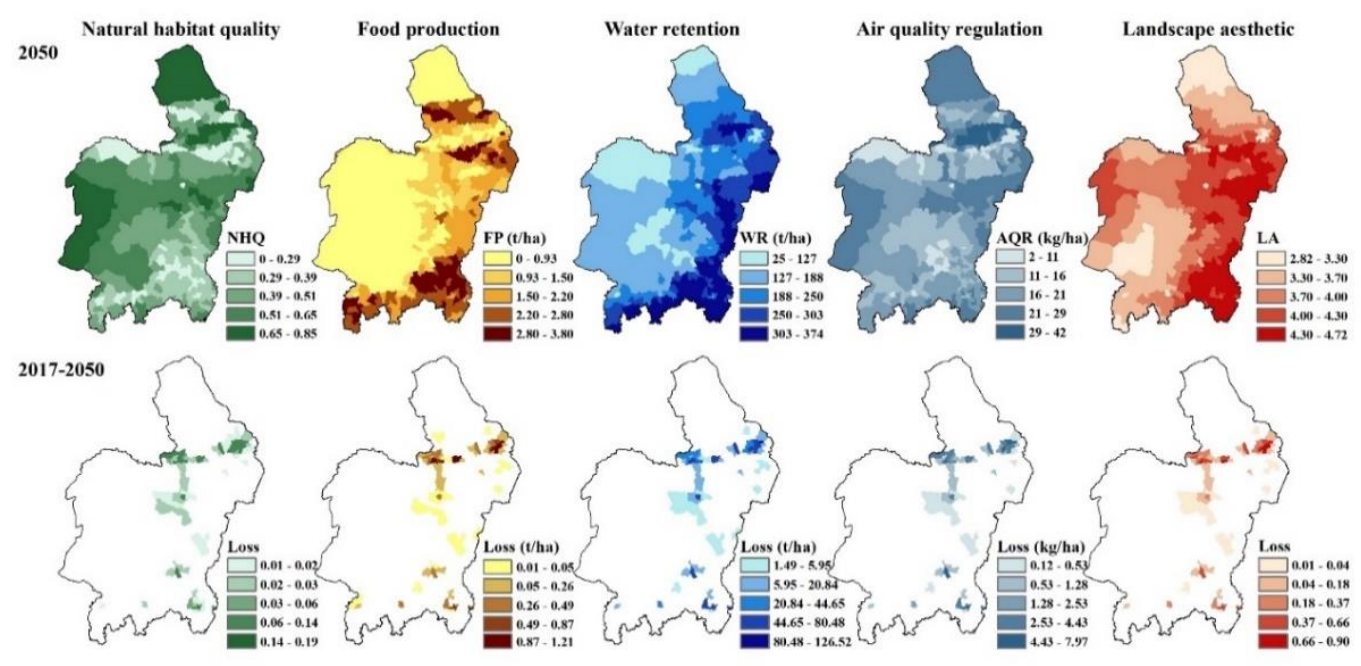

Fig. 6 Potential influences of urban expansion on ecosystem services in HBOY during 2017-2050. Notes: Please refer to figure 4 for an explanation of the abbreviations. 


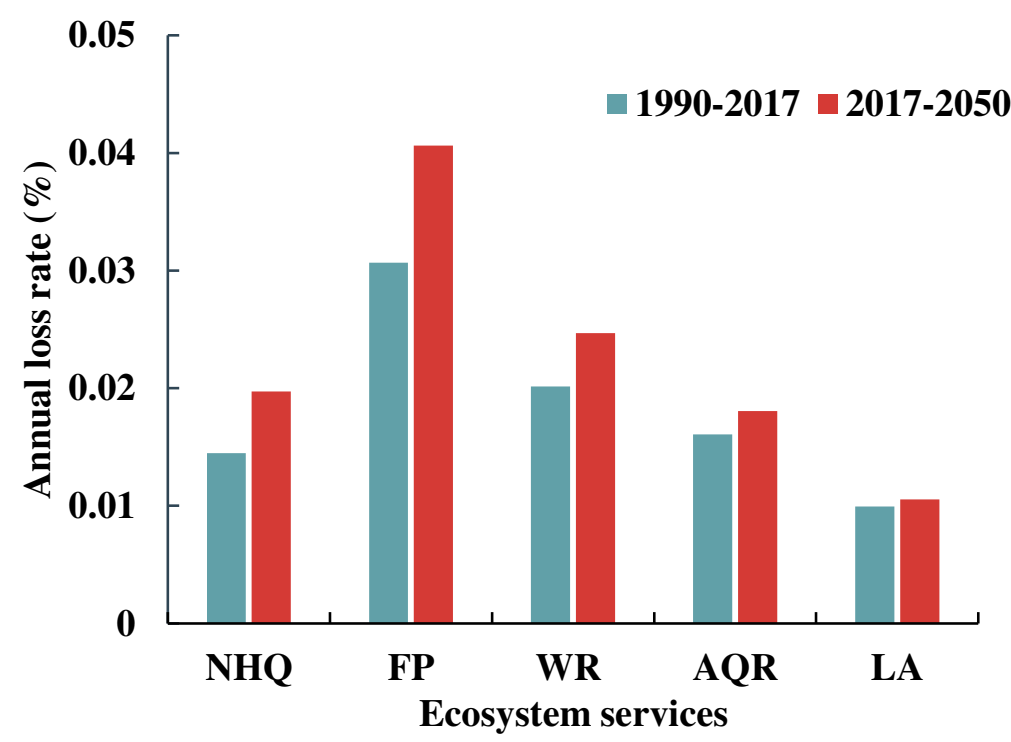

Fig. 7 Comparison of the annual loss rates of ecosystem services in HBOY between 1990-2017 and 2017-2050.

Notes: Please refer to figure 4 for an explanation of the abbreviations.

\section{Discussion}

5.1 Combining the improved LUSD-urban model and ES models can be used to effectively assess the potential influences of future urban expansion on the concurrent loss of multiple ESs in drylands

Improving the LUSD-urban model by the EnKF method can simulate urban expansion more effectively, thereby reducing the uncertainties of evaluating the influences of urban expansion on the concurrent loss of multiple ESs. This is mainly because the EnKF method incorporates more information (e.g., observation data) and constantly optimizes the LUSD-urban model parameters and the simulation results, which reduces the uncertainties introduced by the static model parameters in the LUSD-urban model and eliminates error accumulation and transmission in the model (Li et al., 2020). Therefore, the improved LUSD-urban model is theoretically better than the original model in simulating future urban expansion.

To verify the effectiveness of our method, we estimated the influences of urban expansion on ESs in the HBOY region from 2010 to 2017 by combining the improved LUSD-urban model with ES models and the original LUSD-urban model with ES models. Then, we used historical data from 2010 to 2017 to assess the effectiveness of these two methods. Specifically, based on the urban land area in 2000, we used the improved LUSD-urban model and the original model to simulate the urban land area in 2010. Then, we predicted the urban land in 2017 and compared it with the actual data collected in 2017. Finally, the evaluation results and relative errors of the two methods were calculated. The results showed that the improved LUSD-urban model can more accurately simulate future urban expansion. Based on the urban land data in 2000, we simulated the urban land area in 2010 and calibrated the model. The Kappa coefficient of the improved LUSD-urban model was 0.72 , which was higher than the 0.69 value produced by the original model (Fig. 8). Then, the improved LUSD-urban model and the original model were used to predict the urban land area in 2017, and it 
was found that the Kappa coefficient of the improved LUSD-urban model was 0.64, which was also

456 higher than the 0.59 value output for the original model (Fig. 8).

457 Table 2 Potential influences of urban expansion on ecosystem services in HBOY during 20172050

\begin{tabular}{|c|c|c|c|c|c|c|c|c|c|c|}
\hline & \multicolumn{2}{|l|}{ NHQ } & \multicolumn{2}{|c|}{ FP（t/ha） } & \multicolumn{2}{|c|}{ WR（t/ha） } & \multicolumn{2}{|c|}{ AQR (kg/ha) } & \multicolumn{2}{|l|}{$\mathbf{L A}$} \\
\hline & 2017 & $\begin{array}{l}2017- \\
2050 \\
\text { Loss } \\
(\%)\end{array}$ & 2017 & $\begin{array}{l}2017- \\
2050 \\
\text { Loss } \\
(\%)\end{array}$ & 2017 & $\begin{array}{l}2017- \\
2050 \\
\text { Loss } \\
(\%)\end{array}$ & 2017 & $\begin{array}{l}2017- \\
2050 \\
\text { Loss } \\
(\%)\end{array}$ & 2017 & $\begin{array}{l}2017- \\
2050 \\
\text { Loss } \\
(\%)\end{array}$ \\
\hline HBOY & 0.5096 & 0.65 & 1.32 & 1.34 & 201.30 & 0.81 & 19.01 & 0.60 & 3.84 & 0.35 \\
\hline HН & 0.4726 & 8.91 & 1.48 & 26.75 & 221.89 & 13.55 & 22.30 & 7.99 & 3.87 & 6.56 \\
\hline BT & 0.4677 & 11.52 & 1.30 & 20.65 & 183.50 & 12.04 & 19.70 & 8.94 & 4.11 & 5.19 \\
\hline ER & 0.5661 & 2.77 & 1.20 & 3.06 & 228.12 & 2.67 & 19.89 & 2.47 & 4.05 & 1.06 \\
\hline YL & 0.3449 & 2.00 & 1.34 & 1.84 & 186.58 & 1.82 & 13.29 & 1.90 & 4.02 & 0.64 \\
\hline $\mathbf{T Z}$ & 0.4626 & 4.43 & 1.93 & 5.38 & 257.14 & 3.94 & 24.71 & 2.89 & 4.25 & 1.93 \\
\hline TK & 0.3262 & 0.56 & 2.36 & 0.72 & 237.46 & 0.50 & 17.43 & 0.29 & 4.35 & 0.25 \\
\hline HL & 0.3672 & 0.63 & 2.50 & 0.17 & 278.14 & 0.14 & 20.44 & 0.11 & 4.21 & 0.07 \\
\hline QS & 0.5936 & 0.15 & 1.65 & 0.07 & 310.76 & 0.05 & 24.66 & 0.06 & 4.37 & 0.03 \\
\hline WC & 0.4880 & 0.34 & 2.03 & 0.05 & 274.86 & 0.03 & 23.43 & 0.02 & 3.71 & 0.02 \\
\hline TY & 0.3521 & 3.07 & 2.37 & 5.57 & 239.73 & 3.97 & 18.41 & 2.94 & 4.35 & 1.82 \\
\hline GY & 0.4466 & 0.23 & 2.14 & 0.05 & 233.72 & 0.03 & 20.45 & 0.02 & 3.87 & 0.02 \\
\hline DE & 0.6740 & 0.01 & 1.03 & 0.00 & 165.76 & 0.00 & 23.19 & 0.00 & 3.21 & 0.00 \\
\hline DL & 0.4768 & 0.85 & 1.12 & 2.03 & 176.01 & 0.95 & 16.59 & 0.82 & 4.11 & 0.39 \\
\hline ZG & 0.5722 & 0.13 & 1.36 & 0.05 & 267.21 & 0.06 & 21.93 & 0.07 & 4.32 & 0.03 \\
\hline ETQ & 0.5870 & 0.00 & 0.65 & 0.00 & 150.33 & 0.00 & 18.78 & 0.00 & 3.32 & 0.00 \\
\hline ET & 0.6477 & 0.02 & 0.69 & 0.02 & 147.58 & 0.02 & 21.22 & 0.02 & 3.76 & 0.01 \\
\hline HJ & 0.4670 & 0.02 & 0.63 & 0.02 & 101.36 & 0.02 & 14.13 & 0.02 & 3.77 & 0.01 \\
\hline WS & 0.4866 & 0.00 & 0.55 & 0.01 & 150.15 & 0.00 & 15.04 & 0.00 & 3.54 & 0.00 \\
\hline YJ & 0.6229 & 0.77 & 0.85 & 1.42 & 228.12 & 0.87 & 22.22 & 0.75 & 4.08 & 0.35 \\
\hline $\mathbf{J B}$ & 0.4178 & 0.39 & 1.94 & 0.64 & 279.88 & 0.37 & 18.36 & 0.27 & 3.81 & 0.20 \\
\hline DB & 0.3899 & 0.17 & 2.36 & 0.12 & 260.65 & 0.09 & 17.44 & 0.11 & 3.46 & 0.06 \\
\hline FG & 0.5172 & 0.12 & 2.06 & 0.06 & 306.07 & 0.04 & 20.74 & 0.03 & 4.31 & 0.02 \\
\hline SM & 0.4416 & 0.31 & 1.65 & 0.32 & 251.39 & 0.21 & 17.22 & 0.16 & 4.17 & 0.11 \\
\hline $\mathbf{J X}$ & 0.3223 & 0.22 & 2.93 & 0.01 & 314.61 & 0.01 & 16.41 & 0.01 & 4.50 & 0.01 \\
\hline HS & 0.3308 & 0.41 & 2.49 & 0.15 & 272.41 & 0.14 & 15.80 & 0.15 & 4.25 & 0.07 \\
\hline $\mathbf{M Z}$ & 0.3097 & 1.27 & 3.05 & 1.14 & 324.16 & 0.97 & 16.48 & 0.89 & 4.54 & 0.45 \\
\hline $\mathbf{Z Z}$ & 0.3782 & 2.53 & 2.77 & 2.07 & 338.61 & 1.94 & 19.97 & 2.00 & 4.44 & 0.90 \\
\hline SD & 0.3637 & 4.75 & 2.77 & 2.28 & 335.34 & 2.61 & 20.86 & 2.98 & 4.59 & 1.14 \\
\hline WB & 0.3642 & 5.83 & 2.73 & 4.04 & 318.39 & 4.34 & 18.15 & 4.72 & 4.68 & 1.87 \\
\hline QJ & 0.4708 & 0.38 & 2.31 & 0.03 & 349.80 & 0.04 & 23.28 & 0.03 & 4.60 & 0.02 \\
\hline
\end{tabular}


461

462

463

464

465

466

467

468

469

470

471

472

473

474

475

476
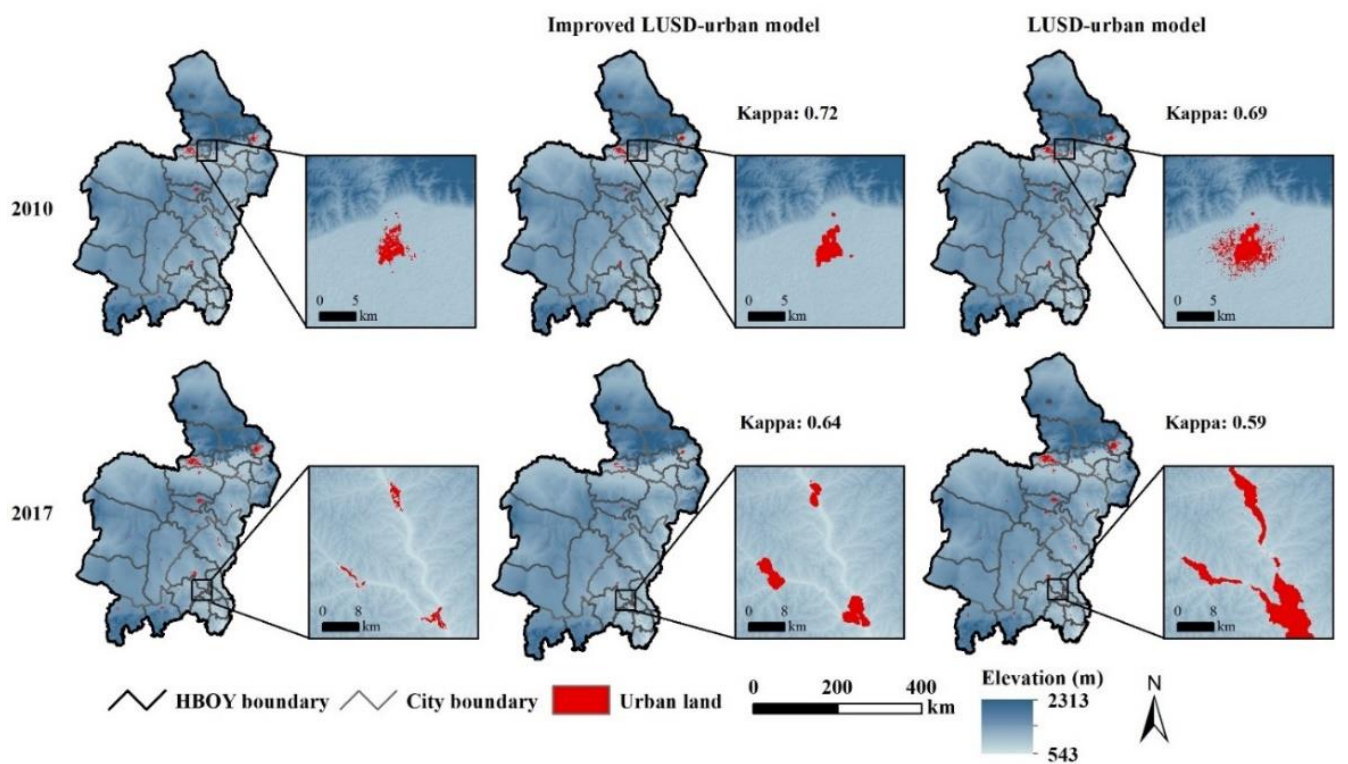

Fig. 8 Comparison of the urban expansion simulated by the improved LUSD-urban model and the original LUSD-urban model in HBOY from 2000 to 2017

The assessment results using the improved LUSD-urban model and the ES models were closer to the true value. Compared with the original LUSD-urban model, the results of combining the improved LUSD-urban and the ES models showed that urban expansion reduced NHQ, FP, WR, AQR, and LA by $11.99 \%, 50.89 \%, 26.77 \%, 17.94 \%$, and $11.72 \%$, respectively, which were closer to the influences of urban expansion on ESs from 2010 to 2017 in the HBOY region (Table 3). In addition, according to $\mathrm{He}$ et al. (2016), the relative error was also selected to further verify the effectiveness of our method. The outcomes revealed that the relative errors of our method were $24.64 \%, 44.94 \%, 18.66 \%, 1.47 \%$, and $8.02 \%$, respectively, which were lower than those of the original LUSD-urban model, and the simulation accuracy was improved by more than $20 \%$ on average (Table 3).

Table 3 Accuracy assessment of the improved LUSD-urban model and the original LUSD-urban model

\begin{tabular}{llllllll}
\hline Ecosystem & $\begin{array}{l}\text { Actual } \\
\text { loss } \\
\text { between }\end{array}$ & $\begin{array}{l}\text { Improved } \\
\text { model }\end{array}$ & LUSD-urban & $\begin{array}{l}\text { Original } \\
\text { model }\end{array}$ & LUSD-urban & $\begin{array}{l}\text { Relative } \\
\text { error } \\
\text { change* }\end{array}$ \\
\cline { 5 - 8 } & $\begin{array}{l}\mathbf{2 0 1 0} \text { and } \\
\mathbf{2 0 1 7}(\%)\end{array}$ & $\begin{array}{l}\text { Simulation } \\
(\%)\end{array}$ & $\begin{array}{l}\text { Relative } \\
\text { error* }(\%)\end{array}$ & $\begin{array}{l}\text { Simulation } \\
(\%)\end{array}$ & $\begin{array}{l}\text { Relative } \\
\text { error }(\%)\end{array}$ & $\begin{array}{l}\text { (\%) } \\
\text { (\%) }\end{array}$ \\
\hline NHQ & 15.91 & 11.99 & -24.64 & 11.98 & -24.70 & 0.25 \\
FP & 35.11 & 50.89 & 44.94 & 52.68 & 50.04 & 10.19 \\
WR & 22.56 & 26.77 & 18.66 & 28.50 & 26.33 & 29.12 \\
AQR & 17.68 & 17.94 & 1.47 & 18.35 & 3.79 & 61.19 \\
LA & 10.85 & 11.72 & 8.02 & 11.83 & 9.03 & 11.22 \\
\hline
\end{tabular}
$100 \%$, where $R E_{S}$ is the simulated result, $R E_{a}$ is the actual result. (3) Relative error change = $\left(R E_{i}-R E_{o}\right) / R E_{o} \times 100 \%$, where $R E_{i}$ is the relative error of the improved LUSD-urban model, $R E_{o}$ is the 


\subsection{Policy implication}

Our study shows that regional urban expansion will ineluctably continue to cause the concurrent loss of multiple ESs, especially for FP and WR. Urban expansion led to a $0.83 \%$ decrease in FP from 1990 to 2017, with the highest impact reaching $14.98 \%$ in Baotou, followed by a $0.54 \%$ decrease in WR, with the highest impact reaching 7.02\% in Baotou. Urban expansion will lead to a $1.34 \%$ reduction in FP during 2017-2050, with the highest impact of $26.75 \%$ in Hohhot, followed by a $0.81 \%$ decrease in WR, with the highest impact of $13.55 \%$ in Hohhot. In addition, both FP and WR showed concurrent losses during these two periods, and the intensity will further expand in the future. The large loss of FP will certainly bring great challenges to regional food security, and the large decline in WR caused by urban expansion will certainly become the main bottleneck of urban development in drylands. Therefore, the protection of FP and WR services should be emphasized in future urban expansion in the HBOY region.

A large amount of cropland and grassland occupied by urban expansion is the dominating reason for the concurrent loss of regional key ESs. We found that the loss of NHQ, FP, WR, AQR, and LA caused by the occupation of cropland and grassland by urban expansion from 1990 to 2017 accounted for more than $70 \%$ of the total loss of each service (Table 4). This proportion will rise to more than $75 \%$ by $2017-2050$ (Table 4 ). In addition, urban expansion in the future will occupy more cropland and grassland, which will be the dominating reason for the enhanced intensity of the concurrent loss of the five ESs. We found that compared with the period from 1990 to 2017, the amount of cropland and grassland occupied by urban expansion will increase by $47.38 \%$ from 2017 to 2050, which will lead to an average 1.44-fold increase in ES losses.

In the future, the local government should strictly control the new urban land occupying a large amount of cropland and grassland through urban planning and management. For example, the policies of "red line of arable farmland" and "ecological redline" should be strictly implemented in the development of urbanization, or the protection of the high-quality cropland and grassland ecosystem should be strengthened to alleviate the potential influences of future urbanization on the concurrent loss of multiple ESs. In addition, future efforts should also aim to control the scale and optimize the spatial pattern of cities to cut down the occupation of cropland and grassland ecosystem by urban expansion. 

cover types in HBOY

\begin{tabular}{|c|c|c|c|c|c|c|c|c|c|c|c|}
\hline \multirow{4}{*}{ Period } & \multirow{4}{*}{$\begin{array}{c}\text { Land } \\
\text { use/cover } \\
\text { types }\end{array}$} & \multirow{2}{*}{\multicolumn{2}{|c|}{$\begin{array}{c}\text { Occupied by } \\
\text { urban land }\end{array}$}} & \multicolumn{8}{|c|}{ Contribution to ecosystem services loss } \\
\hline & & & & \multirow{3}{*}{$\begin{array}{c}\text { NHQ } \\
\text { Percentage } \\
\%\end{array}$} & \multicolumn{2}{|r|}{$\mathbf{F P}$} & \multicolumn{2}{|c|}{ WR } & \multicolumn{2}{|c|}{ AQR } & \multirow{3}{*}{$\begin{array}{c}\text { LA } \\
\text { Percentage } \\
\%\end{array}$} \\
\hline & & Area & Percentage & & Mass & Percentage & Mass & Percentage & Mass & Percentage & \\
\hline & & $\mathrm{km}^{2}$ & $\%$ & & $\times 10^{3} \mathrm{t}$ & $\%$ & $\times 10^{4} \mathrm{t}$ & $\%$ & $\mathrm{t}$ & $\%$ & \\
\hline \multirow{5}{*}{$\begin{array}{l}\text { 1990- } \\
2017\end{array}$} & Cropland & 365.22 & 33.82 & 0 & 163.95 & 85.36 & 8.90 & 48.75 & 336.00 & 23.25 & 50.21 \\
\hline & Forest land & 39.01 & 3.61 & 11.17 & 0 & 0 & 1.12 & 6.16 & 241.86 & 16.74 & 5.19 \\
\hline & Grassland & 321.13 & 29.74 & 73.72 & 28.11 & 14.64 & 8.24 & 45.10 & 867.05 & 60.01 & 44.60 \\
\hline & Water body & 34.17 & 3.16 & 5.87 & 0 & 0 & 0 & 0 & 0 & 0 & 0 \\
\hline & Unused land & 320.44 & 29.67 & 9.22 & 0 & 0 & 0 & 0 & 0 & 0 & 0 \\
\hline \multirow{5}{*}{$\begin{array}{l}2017- \\
2050\end{array}$} & Cropland & 608.53 & 56.35 & 0.00 & 273.18 & 60.16 & 14.83 & 57.16 & 559.85 & 28.32 & 57.03 \\
\hline & Forest land & 53.11 & 4.92 & 12.64 & 0 & 0 & 1.29 & 4.99 & 329.28 & 16.65 & 4.82 \\
\hline & Grassland & 402.98 & 37.31 & 76.82 & 180.91 & 39.84 & 9.82 & 37.85 & 1088.05 & 55.03 & 38.15 \\
\hline & Water body & 47.59 & 4.41 & 6.80 & 0 & 0 & 0 & 0 & 0 & 0 & 0 \\
\hline & Unused land & 155.08 & 14.36 & 3.73 & 0 & 0 & 0 & 0 & 0 & 0 & 0 \\
\hline
\end{tabular}

Note: Please refer to Table 1 for an explanation of the abbreviations.

513

\subsection{Future perspectives}

Our study proposed a new approach to effectively assess the potential impacts of future urban expansion on the concurrent loss of multiple ESs in drylands. We combined the improved LUSDurban model with ES models and used the HBOY urban agglomeration to verify the method effectiveness. The results revealed that our method improved the accuracy of the assessment by more than $20 \%$ on average, among which the accuracy of assessing the influences of urban expansion on WR and AQR improved the most by $61.19 \%$ and $29.12 \%$, respectively.

There are also some uncertainties in this study. First, the linear regression model was simply used to determine the future urban population and urban land demand. However, the relationships between economy, population, environment, policy and urban expansion are very complex. Second, the quantification of ESs supply based on LULC data in this study was relatively simple, which may lead to the underestimation of the impacts of urban expansion on the studied ESs. For example, the influences of urban land on ESs due to the occupation of water bodies were ignored in this study. However, this does not impact the dependability of the results of our study. This is because these quantitative methods have been fully applied and verified in existing studies (Yang et al., 2015; Landuyt et al., 2016; Xie et al., 2018), and the occupation of water bodies by regional urban expansion is considered to be relatively minimal, so the influences of urban expansion on the concurrent loss of multiple ESs can be accurately depicted in our study.

In the future, we will use the mechanism model (such as system dynamics model) to predict the future urban land demand based on the analysis of the driving mechanism of urban expansion. In addition, we will further explore more effective and accurate methods of mapping ESs, thereby reducing the uncertainties of the assessment results. 
537 Our method can be used to effectively assess the potential influences of future urban expansion on the concurrent loss of multiple ESs in drylands. First, the improved LUSD-urban model was obviously superior to the original LUSD-urban model in the urban land simulation. The Kappa value of the improved LUSD-urban model in simulating urban land in 2017 was 0.64, which was higher than the 0.59 value of the original model. Second, compared with the original model, the influences of regional urban expansion on multiple ESs evaluated by combining the improved LUSD-urban model and ES models were closer to the actual value, with smaller relative errors. The accuracy of the assessment was improved by more than $20 \%$ on average. Among them, the accuracy associated with evaluating the influences of urban expansion on WR and AQR services improved the most at $61.19 \%$ and $29.12 \%$, respectively.

547

548

549

550

551

552

553

554

555

556

557

558

559

560

561

562

563

564

565

566

567

568

\section{9}

570

571

572
Under the influence of urban expansion from 1990 to 2017, FP, WR, AQR, NHQ, and LA in HBOY showed a downward trend, which decreased by $0.83 \%, 0.54 \%, 0.43 \%, 0.39 \%$, and $0.26 \%$, respectively. During 2017-2050, urban expansion will accelerate the decline of these five key ESs, and the average annual loss will reach $4.06 \%$, 2.47\%o, 1.81\%o, 1.97\%o and 1.05\%, which will be higher than that of the $3.06 \%$, 2.01\%o, 1.61\%o, 1.45\%o and $0.99 \%$ osses that occurred during 1990 2017. At the same time, future urban expansion will lead to the concurrent loss of five pairs of ESs, and the magnitude of the concurrent loss will be further intensified. The correlation coefficients between them will increase from $0.52-0.86$ to $0.57-0.87$. Urban expansion in the future will occupy more cropland and grassland, which will be the dominating reason for the concurrent loss of multiple ESs. Compared with 1990-2017, the cropland and grassland occupied by urban expansion will increase by $47.38 \%$ in $2017-2050$, which will lead to an average increase of 1.44 times the loss of ESs.

Therefore, we suggest that the future urban expansion encroaching on large amounts of cropland and grassland should be strictly controlled in urban planning and management to reduce the risk of the impact of urban expansion on multiple regional ESs, especially for cities undergoing rapid urban expansion and serious impacts on ESs, such as Hohhot and Baotou.

\section{Acknowledgments}

This work was supported by the National Natural Science Foundation of China (Grant No. 41971270). It was also supported by the Second Tibetan Plateau Scientific Expedition and Research Program (Grant No. 2019QZKK0405) and the National Natural Science Foundation of China (Grant No. 41971271).

\section{Ethics declarations}

\section{Conflicts of interest}

The authors declare that they have no conflict of interest. 
Bai, X. M., Shi, P. J., Liu, Y. S. 2014. Realizing China's urban dream. Nature, 509: 158-160.

Cui F. Q., Tang, H. P., Zhang, Q., Wang, B. J., Dai, L. W. (2019). Integrating ecosystem services supply and demand into optimized management at different scales: A case study in Hulunbuir, China. Ecosystem Services, 39.

Geist, H. J., Lambin, E. F. (2004). Dynamic causal patterns of desertification. Bioscience, 54(9): 817-829.

Gomes, L. C., Bianchi, F. J. J. A., Cardoso, I. M. Fernandes Filho, E. I. Schulte, R. P. O. (2020). Land use change drives the spatio-temporal variation of ecosystem services and their interactions along an altitudinal gradient in Brazil. Landscape Ecology, 35, 1571-1586.

Gong, B. H., Liu, Z. F. (2021). Assessing impacts of land use policies on environmental sustainability of oasis landscapes with scenario analysis: the case of northern China. Landscape Ecology, 36, 1913-1932.

He, C. Y., Liu, Z. F., Tian, J., Ma, Q. (2014). Urban expansion dynamics and natural habitat loss in China: a multiscale landscape perspective, Global Change Biology, 20(9): 2886-2902.

He, C. Y., Zhang, D., Huang, Q. X., Zhao, Y. Y. (2016). Assessing the potential impacts of urban expansion on regional carbon storage by linking the LUSD-urban and InVEST models. Environmental Modelling \& Software, 75, 44-58.

Hou, Y. Z., Zhao, W. W, Liu, Y. X., Yang, S. Q., Hu, X. P., Cherubini, F. (2021). Relationships of multiple landscape services and their influencing factors on the Qinghai-Tibet Plateau. Landscape Ecology, 36, 1987-2005.

Landuyt, D., Broekx, S., Engelen, G., Uljee, I., Van der Meulen, M., Goethals, P. L. (2016). The importance of uncertainties in scenario analyses: A study on future ecosystem service delivery in Flanders. Science of the Total Environment, 553: 504-518.

Li, S.C., Ma, C., Wang, Y., Wang, Y., Zhu, W. B., Liu, J. L., Li, X. J., Li, Y., Zhang, J., Gao, Y. (2014). The Geography of Ecosystem Services. Science Press, Beijing (in Chinese).

Li, X, Liu, F, Fang, M. (2020). Harmonizing models and observations: Data assimilation in Earth system science. Science China Earth Sciences, 63:1059-1068, https://doi.org/10.1007/s11430-019-9620-x

Liu, J. Y., Zhang, Z. X., Xu, X. L., Kuang, W. H., Zhou, W. C., Zhang, S. W., Li, R. D., Yan, C. Z., Yu, D. S., Wu, S. X., Jiang, N., (2010). Spatial patterns and driving forces of land use change in China during the early 21st century, Journal of Geographical Sciences 20(4):483-494.

Lyu, R. F., Zhang, J. M., Xu, M. Q., Li, J. J. (2018). Impacts of urbanization on ecosystem services and their temporal relations: A case study in Northern Ningxia, China. Land Use Policy, 77, 163-173.

Millennium Ecosystem Assessment (MEA). (2005). Ecosystems and human well-being. synthesis. Washington DC: Island Press, 2005.

National Development and Reform Commission. (2018). The plan for Hohhot-Baotou-Ordos-Yulin cluster. www.gov.cn/xinwen/2018-03/07/content_5271788.htm, 2019-08-04.

Nelson, E., Sander, H., Hawthorne, P., Conte, M., Ennaanay, D., Wolny, S., Manson, S., Polasky, S. (2010). Projecting Global Land-Use Change and Its Effect on Ecosystem Service Provision and Biodiversity with Simple Models. Plos ONE 5, e14327.

Pickard, B. R., Van Berkel, D., Petrasova, A., Meentemeyer, R. K. (2016). Forecasts of urbanization scenarios reveal trade-offs between landscape change and ecosystem services. Landscape Ecology, 32(3), 617-634.

Sakov, P., Bertino, L. (2011). Relation between two common localisation methods for the EnKF. Computational Geosciences, 15(2), 225-237.

Seto, K. C., Guneralp, B., Hutyra, L. R. (2012). Global forecasts of urban expansion to 2030 and direct impacts on biodiversity and carbon pools, Proceedings of the National Academy of Sciences of the United States of 
America, 109(40): 16083-16088.

Sharp, R., Tallis, H. T., Ricketts, T. Guerry, A. D., Wood, S. A., Chapin-Kramer, R., Nelson, E., Ennaanay, D., Wolny, S., Olwero, N., Vigerstol, K., Pennington, D., Mendoza, G., Aukema, J., Foster, J., Forrest, J., Cameron, D., Arkema, K., Lonsdorf, E., Kennedy, C., Verutes, G., Kim, C. K., Guannel, G., Papenfus, M., Toft, J., Marsik, M., Bernhardt, J., Griffin, R., Gowinski, K., Chaumont, N., Perelman, A., Lacayo, M. M., Hamel, P., Vogl, A. L., Bierbower. (2016). InVEST 3.2.0 User's Guide. The Natural Capital Project, Stanford University, University of Minnesota, The Nature Conservancy, and World Wildlife Fund.

Song, S. X., Liu, Z. F., He, C. Y., Lu, W. L. (2020). Evaluating the effects of urban expansion on natural habitat quality by coupling localized shared socioeconomic pathways and the land use scenario dynamics-urban model. Ecological Indicators, 112, 106071.

Sun, Z. X., Liu, Z. F., He, C. Y., Wu, J. G. (2017). Impacts of urban expansion on ecosystem services in the drylands of northern China: A case study in the Hohhot-Baotou-Ordos urban agglomeration region. Journal of Natural Resources, 32(10): 1691-1704 (in Chinese).

Xie, W. X., Huang, Q. X., He, C. Y., Zhao, X. (2018). Projecting the impacts of urban expansion on simultaneous losses of ecosystem services: A case study in Beijing, China. Ecological Indicators, 84, 183-193.

Yang, G. F., Ge, Y., Xue, H., Yang, W., Shi, Y., Peng, C. H., Du, Y. Y., Fan, X., Ren, Y., Chang, J. (2015). Using ecosystem service bundles to detect trade-offs and synergies across urban-rural complexes. Landscape and Urban Planning, 136: 110-121.

Yang, Y. M., N, Y., Liu, Z. F., Zhang, D., Sun, Y. H. (2020). Direct and indirect losses of natural habitat caused by future urban expansion in the transnational area of Changbai Mountain. Sustainable Cities and Society, 63.

Zhang, B., Xie, G. D., Zhang, C. Q., Jing, Z. (2012). The economic benefits of rainwater-runoff reduction by urban green spaces: A case study in Beijing, China. Journal of Environmental Management, 100(10): 65-71.

Zhang, D., Huang, Q. X., He, C. Y., Wu, J. G. (2017). Impacts of urban expansion on ecosystem services in the Beijing-Tianjin-Hebei urban agglomeration, China: A scenario analysis based on the Shared Socioeconomic Pathways. Resources, Conservation and Recycling, 125, 115-130.

Zhang, Y. H., Li, X., Liu, X. P., Qiao, J. G. (2015). Self-modifying CA model using dual ensemble Kalman filter for simulating urban land-use changes, International Journal of Geographical Information Science, 29:9, 16121631.

Zhou, Y. R., Varquez, A. C. G., Kanda, M. (2019). High-resolution global urban growth projection based on multiple applications of the SLEUTH urban growth model. Scientific Data, 6. 